\title{
Chemical shift assignments of calmodulin bound to the $\beta$-subunit of a retinal cyclic nucleotide-gated channel (CNGB1)
}

\author{
Aritra Bej ${ }^{1}$. James B. Ames ${ }^{1}$ (D) \\ Received: 6 December 2021 / Accepted: 24 January 2022 / Published online: 2 February 2022 \\ (c) The Author(s) 2022
}

\begin{abstract}
Rod cyclic nucleotide-gated (CNG) channels are formed by two protein subunits (CNGA1 and CNGB1). Calmodulin $(\mathrm{CaM})$ binds to the cytosolic regulatory domain of CNGB1 and decreases the open probability of CNGA1/CNGB1 channels. The CaM binding site within bovine CNGB1 (residues 679-702) binds tightly to $\mathrm{Ca}^{2+}$-bound CaM, which promotes $\mathrm{Ca}^{2+}$-induced inactivation of CNGA1/CNGB1 channels in retinal rods. We report complete NMR chemical shift assignments of $\mathrm{Ca}^{2+}$-saturated CaM bound to the CaM-binding domain of CNGB1 (BMRB no. 51222).
\end{abstract}

Keywords CaM $\cdot$ Calcium $\cdot$ CNGB1 $\cdot$ Retina $\cdot$ Photoreceptor $\cdot$ NMR

\section{Biological context}

Cyclic nucleotide-gated (CNG) channels expressed in retinal rods conduct a cation current in response to changes in intracellular levels of cGMP that occur during visual phototransduction (Baylor 1996, Fesenko, Kolesnikov et al. 1985). $\mathrm{Ca}^{2+}$-dependent regulation of photoreceptor CNG channels by CaM is important for promoting light adaptation in photoreceptor cells (Bradley et al. 2005, Fain et al. 2001, Hsu and Molday 1993). Retinal CNG channels consist of two protein subunits, CNGA1 and CNGB1 (Bradley et al. 2001). The CNGA1 subunit can form a functional homotetrameric channel when expressed alone, whereas CNGB1 does not form a functional homomeric channel (Finn et al. 1998). Native CNG channels in retinal rods form a heteromeric tetramer comprised of a 3:1 stoichiometry of CNGA1:CNGB1 (Shuart, Haitin et al., 2011). Three CNGA1 subunits form a trimer that binds tightly with a single CNGB1 subunit in a $\mathrm{Ca}^{2+}$-dependent fashion. The $\mathrm{Ca}^{2+}$ sensor protein, calmodulin $(\mathrm{CaM})$ binds to a cytosolic site in CNGB1 (residues 679-702) (Trudeau and Zagotta 2002) that may regulate CNGB1 binding to CNGA1 (Shuart et al. 2011) and perhaps mediate $\mathrm{Ca}^{2+}$-induced $\mathrm{CNG}$ channel inactivation in rod cells (Hsu and Molday 1993; Trudeau and

James B. Ames

jbames@ucdavis.edu

1 Department of Chemistry, University of California, Davis, CA 95616, USA
Zagotta 2003). Defects in the $\mathrm{Ca}^{2+}$-dependent regulation of CNG channels are genetically linked to autosomal recessive retinitis pigmentosa and other inherited forms of blindness (Bareil, Hamel et al. 2001). Elucidating the CNG channel structural interaction with $\mathrm{CaM}$ may provide insights for the treatment of retinal diseases.

Although structures are known for $\mathrm{CaM}$ bound to the CNGA2 subunit from olfactory CNG channels (Contessa et al. 2005), atomic level structural information is currently not known for CaM bound to the retinal CNGB1. We report here NMR resonance assignments of $\mathrm{Ca}^{2+}$-saturated $\mathrm{CaM}$ bound to the CaM-binding domain of CNGB1 (hereafter called CaM/CNGB1). These assignments are a first step toward elucidating the structure of CaM bound to CNGB1.

\section{Methods and experiments}

\section{Expression and purification of CaM}

Recombinant human CaM was subcloned into pET11b expression vector (Novagen) and overexpressed in E. coli strain BL21(DE3) as described previously (Turner, Anderson et al. 2020). Uniformly ${ }^{13} \mathrm{C} /{ }^{15} \mathrm{~N}$-labeled CaM samples were overexpressed in M9 minimal media, containing $1 \mathrm{~g} / \mathrm{L}$ ${ }^{15} \mathrm{NH}_{4} \mathrm{Cl}$ and $3 \mathrm{~g} / \mathrm{L}{ }^{13} \mathrm{C}$-labeled glucose (Cambridge Isotopes Laboratories) as the sole nitrogen and carbon sources, respectively. The soluble fraction of the cell lysate was loaded onto a HiPrep Phenyl Sepharose 6 column that was 
pre-equilibrated with equilibration buffer, containing $20 \mathrm{mM}$ Tris (pH 7.5), $200 \mathrm{mM} \mathrm{KCl,} 2 \mathrm{mM} \mathrm{CaCl}_{2}$. The CaM protein was eluted from the column using a buffer that contained 20 $\mathrm{mM}$ Tris ( $\mathrm{pH}$ 7.5), $50 \mathrm{mM} \mathrm{KCl}, 2 \mathrm{mM}$ EGTA. The eluted protein fraction was further loaded onto a HiPrep Q Sepharose anion exchange column that was pre-equilibrated with $50 \mathrm{mM}$ Tris (pH 7.5), $25 \mathrm{mM} \mathrm{KCl}, 1 \mathrm{mM}$ EGTA and eluted by a $\mathrm{KCl}$ gradient up to $625 \mathrm{mM}$. The purity and identity of the eluted protein fractions were confirmed by sodium dodecyl sulfate-polyacrylamide gel electrophoresis. A peptide fragment of the CaM binding domain from CNGB1 (residues 679-702) was purchased from GenScript, dissolved in DMSO- $\mathrm{d}_{6}$, and quantified using UV-Vis absorption spectroscopy. A 1.7-fold excess of the peptide was added to $\mathrm{Ca}^{2+}$-bound $\mathrm{CaM}$, incubated at room temperature for $30 \mathrm{~min}$, and concentrated to $0.5 \mathrm{mM}$.

\section{NMR spectroscopy}

Protein samples of ${ }^{15} \mathrm{~N}$ - or ${ }^{13} \mathrm{C} /{ }^{15} \mathrm{~N}$-labeled CaM bound to unlabeled CNGB1 peptide were exchanged into NMR buffer containing $20 \mathrm{mM}$ Tris- $\mathrm{d}_{11}$ (pH 7.0) with $1 \mathrm{mM} \mathrm{CaCl}_{2}$, and $92 \% \mathrm{H}_{2} \mathrm{O} / 8 \% \mathrm{D}_{2} \mathrm{O}$. The $\mathrm{CaM} / \mathrm{CNGB} 1$ complex was concentrated to give a final concentration of $0.5 \mathrm{mM}$ in a final volume of $0.3 \mathrm{~mL}$. All NMR experiments were performed at $308 \mathrm{~K}$ on a Bruker Avance III $600 \mathrm{MHz}$ spectrometer equipped with a four-channel interface and triple resonance cryogenic (TCI) probe. The ${ }^{15} \mathrm{~N}-{ }^{1} \mathrm{H}$ HSQC spectrum (Fig. 1A, B) was recorded with $256 \times 2048$ complex points for ${ }^{15} \mathrm{~N}(\mathrm{~F} 1)$ and ${ }^{1} \mathrm{H}(\mathrm{F} 2)$. Assignment of backbone resonances was obtained by analyzing the following spectra: HNCACB, $\mathrm{CBCA}(\mathrm{CO}) \mathrm{NH}, \mathrm{HNCO}$ and $\mathrm{HBHA}(\mathrm{CO}) \mathrm{NH}$. The assignment of side chain (aliphatic (Fig. 1C) and aromatic) resonances was obtained by analyzing the following spectra: HCCCONH-TOCSY, HCCH-TOCSY, HBCBCGCDHD and HBCBCGCDCEHE as described previously (Ikura et al. 1991). The NMR data were processed using NMRPipe and analyzed using Sparky.

\section{Extent of assignments and data deposition}

Figure 1A, B present the ${ }^{15} \mathrm{~N}-{ }^{1} \mathrm{H}$ HSQC spectrum of CaM/ CNGB1 to illustrate representative backbone resonance assignments. Figure $1 \mathrm{C}$ presents a constant-time ${ }^{13} \mathrm{C}-{ }^{1} \mathrm{H}$ HSQC spectrum to illustrate side chain methyl resonance assignments. The NMR assignments were based on 3D heteronuclear NMR experiments performed on ${ }^{13} \mathrm{C} /{ }^{15} \mathrm{~N}$-labeled CaM bound to unlabeled CNGB1 peptide. The NMR spectra of CaM/CNGB1 exhibited well-dispersed peaks indicative of a stably folded structure. Four amide resonances (assigned to G26, G62, G99 and G135) exhibited noteworthy downfield shifts that are caused by $\mathrm{Ca}^{2+}$ binding to each of the four EF-hands (Fig. 1A). Ring current shifted methyl resonances assigned to residues I28, V36, and I101 (Fig. 1C) suggest these methyl groups are near aromatic residues in the hydrophobic core. More than $85 \%$ of the backbone resonances $\left({ }^{1} \mathrm{HN},{ }^{15} \mathrm{~N},{ }^{13} \mathrm{C} \alpha,{ }^{13} \mathrm{C} \beta\right.$, and $\left.{ }^{13} \mathrm{CO}\right)$ and $83 \%$ of aliphatic and aromatic side-chain resonances were assigned. A stretch of ten residues (residues 68-78) in the second EFhand of $\mathrm{CaM}$ could not be assigned (central gap near $\mathrm{H} 4$ in Fig. 2), because their HSQC peaks were either broadened beyond detection or otherwise could not be detected. The observed peak broadening here suggests that these residues might undergo conformational exchange processes perhaps caused by their interaction with the bound peptide. Indeed, these same resonances are exchange broadened in $\mathrm{CaM}$ bound to the $\alpha$-subunit of the retinal cyclic nucleotidegated channel (CNGA2) (Contessa et al. 2005), but are not exchange broadened in free CaM (Kainosho et al. 2006). The chemical shift assignments $\left({ }^{1} \mathrm{H},{ }^{15} \mathrm{~N},{ }^{13} \mathrm{C}\right)$ for $\mathrm{CaM} / \mathrm{CNGB} 1$ have been deposited in the BioMagResBank (http://www. bmrb.wisc.edu) under accession number 51222 .

The secondary structure of CaM/CNGB1 was calculated based on the chemical shift index (Wishart et al. 1992) of each assigned amino acid residue and ANN-Secondary structure prediction using TALOS+ (Shen et al. 2009) (Fig. 2). CaM/CNGB 1 contains the following $\alpha$-helices: H1 (residues 7-20), H2 (residues 30-39), H3 (residues 46-55), H5 (residues 83-93), H6 (residues 103-112), H7 (residues 119-129) and H8 (residues 139-143) depicted by cylinders in Fig. 2A. Four short $\beta$-strands named S1 (residues 27-28), S2 (residues 63-65), S3 (residues 100-102) and S4 (residues 136-137) are depicted by the triangles in Fig. 2A. Preliminary NMR-derived distance restraints inferred from NOESY spectra suggest that the observed $\alpha$-helices and $\beta$-strands combine to form $4 \mathrm{EF}-$ hand $\mathrm{Ca}^{2+}$ binding motifs (EF1: residues 7-39, EF2: residues 45-76, EF3: residues 83-112 and EF4: residues 119-144) as seen in the crystal structure of $\mathrm{CaM}$ in the absence of peptide (Babu et al. 1988). In the $\mathrm{CaM}$ crystal structure, the N-terminal EF-hands (EF1 and $\mathrm{EF} 2$ ) interact to form what is called the N-lobe, while EF3 and EF4 interact to form the C-lobe. The binding of the CNGB1 peptide to CaM causes detectable chemical shift perturbations that are distributed uniformly throughout both the N-lobe and C-lobe of CaM (Fig. 3). Thus, the CNGB1 peptide is likely making contact with both lobes of $\mathrm{CaM}$, consistent with the familiar collapsed structure of $\mathrm{CaM}$ bound to other peptide targets (Hoeflich and Ikura 2002). The CaM residues (A16, L19, L33, M52, A89, L106, M110 and F142) that have relatively high CSP values in Fig. 3 correspond to the residues that directly contact the CNGA2 peptide in the NMR structure of CaM/CNGA2 (Contessa et al. 2005). The NMR assignments of CaM/CNGB1 presented here are an important first step toward determining its full three-dimensional structure. 


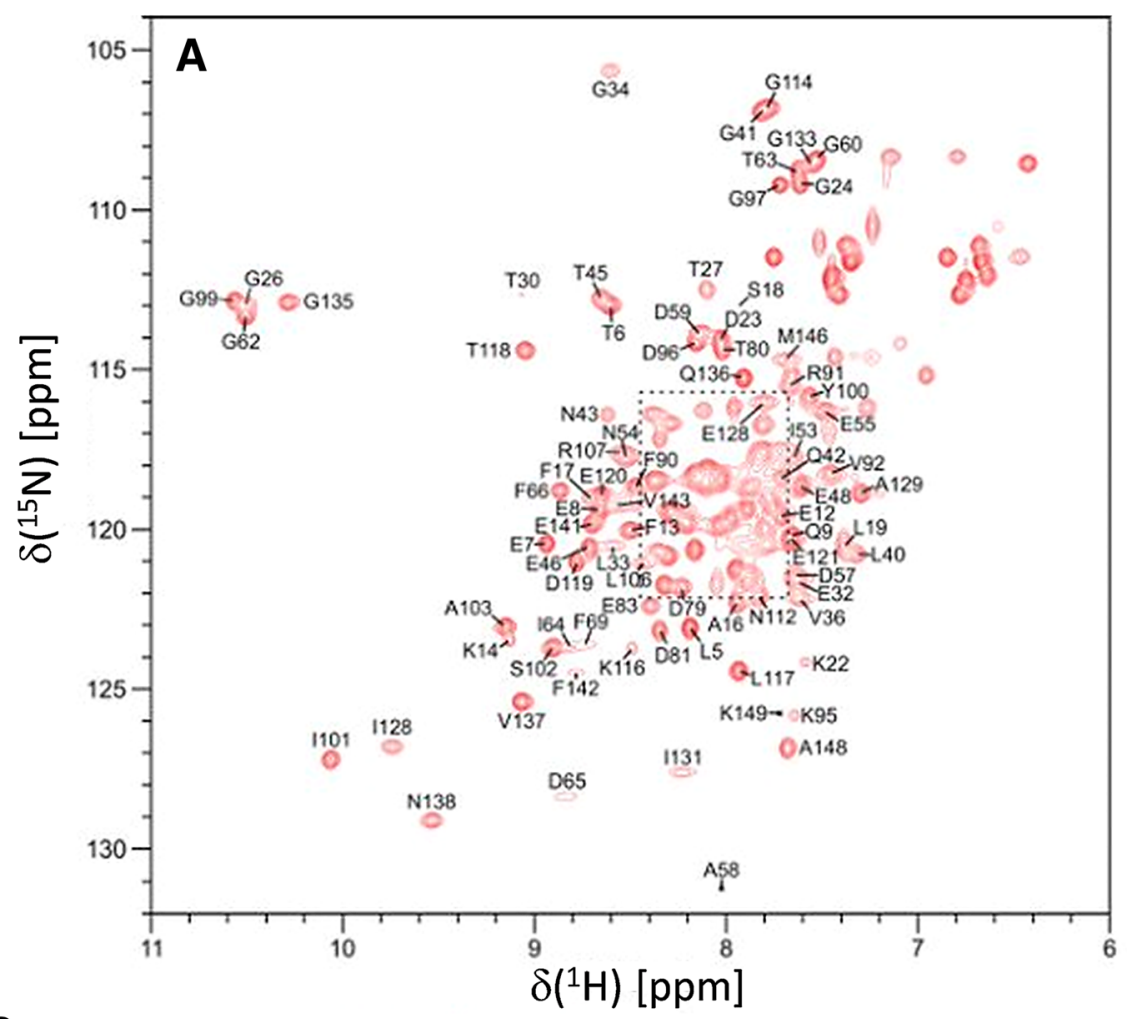

B

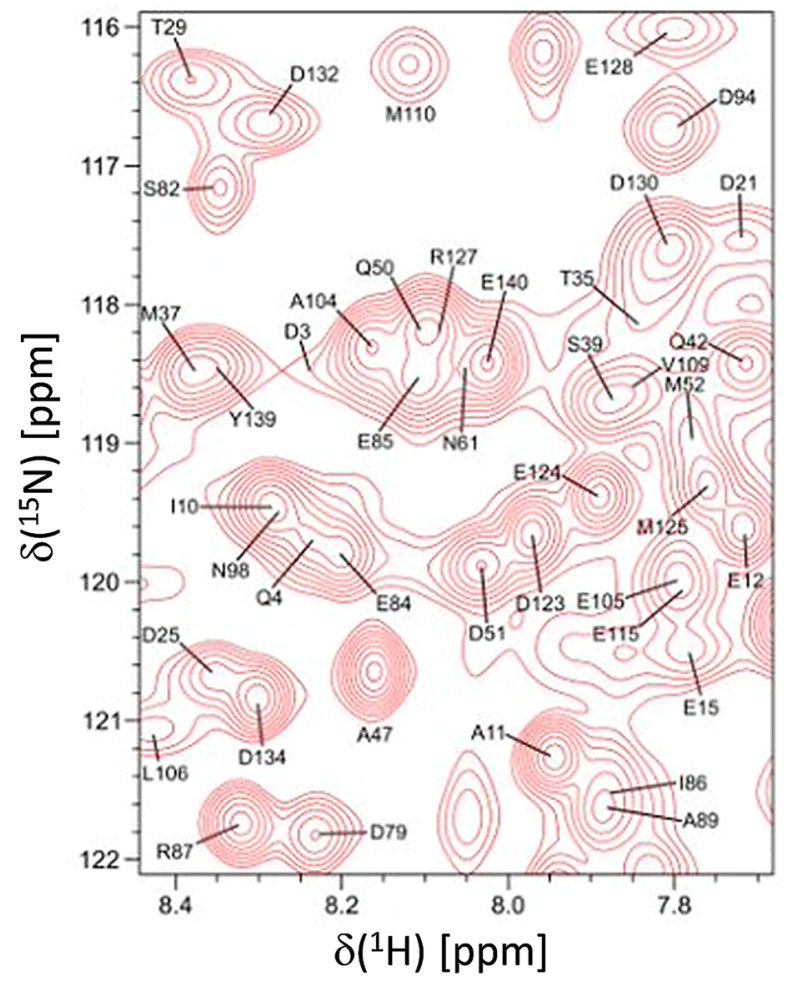

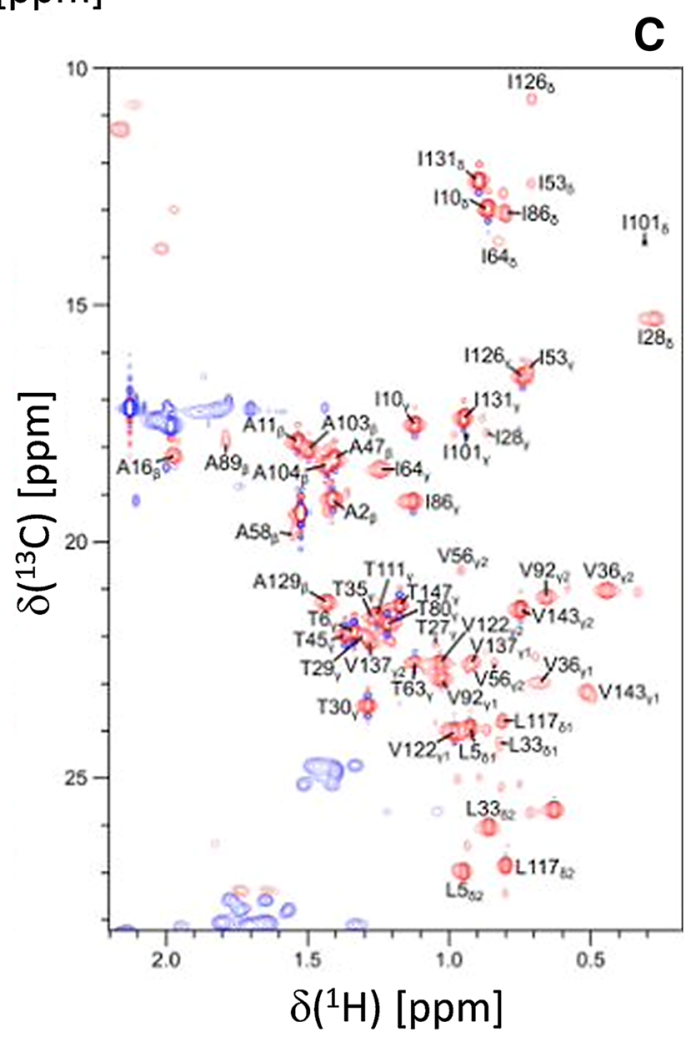

Fig. 1 Two-dimensional NMR spectra of CaM bound to unlabeled CNGB1-CaMBD peptide. A ${ }^{15} \mathrm{~N}-{ }^{1} \mathrm{H}$ HSQC spectrum recorded at $600 \mathrm{MHz}{ }^{1} \mathrm{H}$ frequency was analyzed to determine backbone resonance assignments. B Expanded view of resonance assignments from the spectrally crowded region highlighted by the dashed box. C Con- stant-time ${ }^{13} \mathrm{C}-{ }^{1} \mathrm{H}$ HSQC spectrum was analyzed to determine side chain resonance assignments. Representative resonance assignments are indicated by residue labels; complete assignments are available as BMRB accession no. 51222 


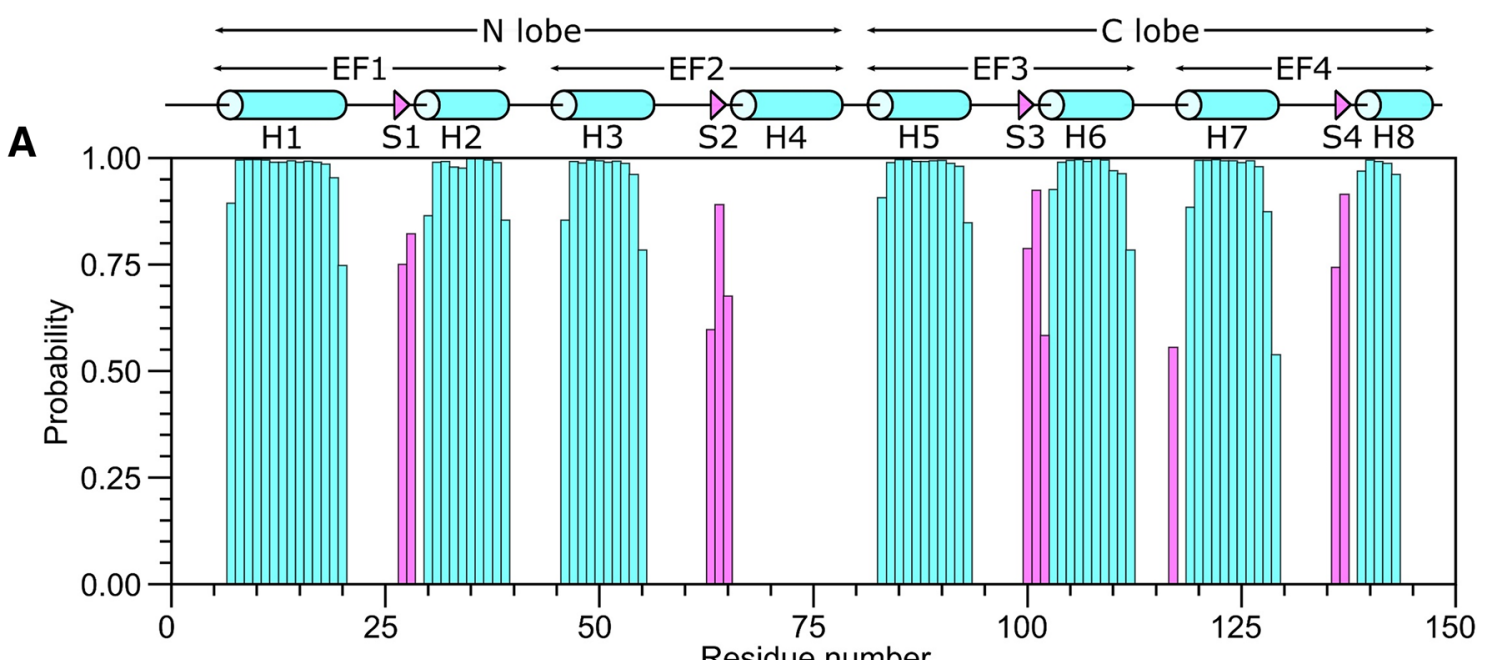

B



Fig. 2 Secondary structure and order parameters of $\mathrm{Ca}^{2+}$-saturated CaM bound to unlabeled CNGB1 peptide predicted from the assigned backbone chemical shifts. A Probability of secondary structural elements (cyan for helix and magenta for strand) and B RCI order parameter $\left(\mathrm{RCI}-\mathrm{S}^{2}\right)$ of $\mathrm{Ca}^{2+}$-saturated $\mathrm{CaM}$ bound to unlabeled
CNGB1 peptide were predicted using TALOS+ server (Shen et al. 2009). The wire diagram depicting the secondary structural elements (cylinder for helix and triangle for strand) was obtained from the CaM structure [PDB ID_2VAY (Halling et al. 2009)]

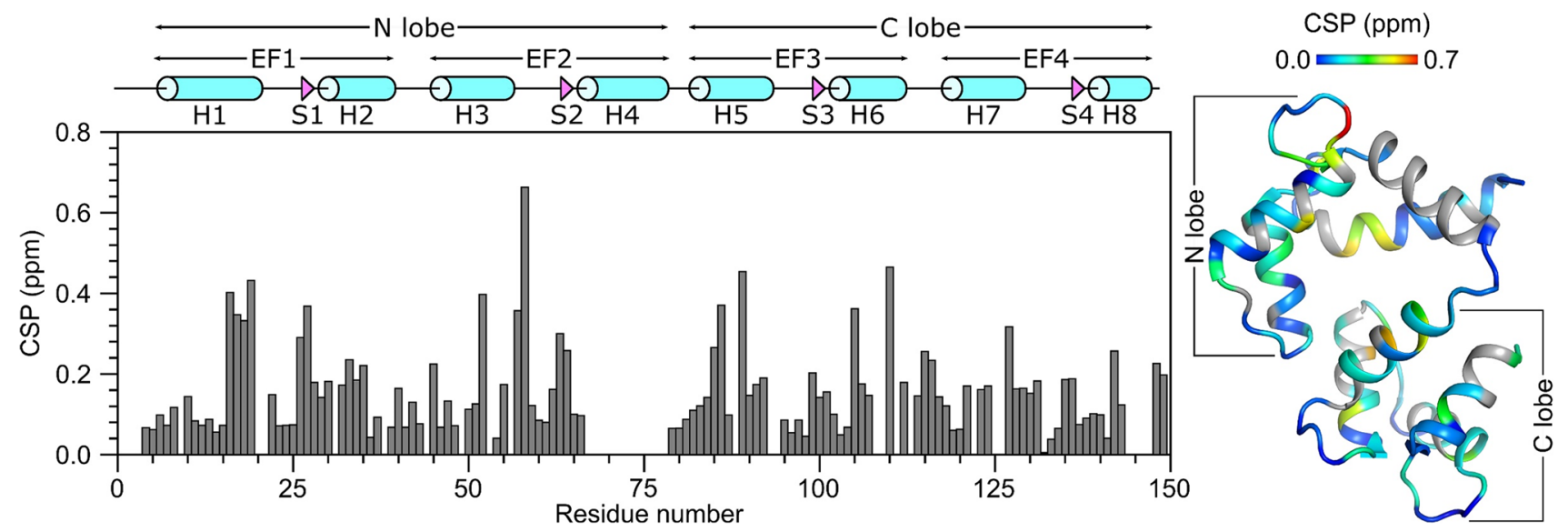

Fig. 3 Residue-specific amide chemical shift perturbation (CSP) for $\mathrm{Ca}^{2+}$-bound $\mathrm{CaM}$ in the presence and absence of CNGB1 peptide. CSP was calculated as: $C S P=\sqrt{\left(\Delta H^{N}\right)^{2}+(\Delta N)^{2}} . \Delta \mathrm{H}^{\mathrm{N}}$ and $\Delta \mathrm{N}$ are the observed difference in the ${ }^{1} \mathrm{H}^{\mathrm{N}}$ and ${ }^{15} \mathrm{~N}$ chemical shifts, respectively for CaM/CNGB1 compared to CaM alone. CSP values are mapped on to the CaM structure (PDB ID: 2VAY (Halling et al. 2009)) 
Acknowledgements We thank Derrick Kaseman and Ping Yu for technical support and help with NMR experiments. Work supported by NIH Grants (EY012347) to J.B.A and (RR11973) to the UC Davis NMR facility.

Data availability The assignments have been deposited to the BMRB under the accession code: 51222 .

Open Access This article is licensed under a Creative Commons Attribution 4.0 International License, which permits use, sharing, adaptation, distribution and reproduction in any medium or format, as long as you give appropriate credit to the original author(s) and the source, provide a link to the Creative Commons licence, and indicate if changes were made. The images or other third party material in this article are included in the article's Creative Commons licence, unless indicated otherwise in a credit line to the material. If material is not included in the article's Creative Commons licence and your intended use is not permitted by statutory regulation or exceeds the permitted use, you will need to obtain permission directly from the copyright holder. To view a copy of this licence, visit http://creativecommons.org/licenses/by/4.0/.

\section{References}

Babu YS, Bugg CE, Cook WJ (1988) Structure of calmodulin refined at 2.2 A resolution. J Mol Biol 204:191-204

Bareil C, Hamel CP, Delague V, Arnaud B, Demaille J, Claustres M (2001) Segregation of a mutation in CNGB1 encoding the betasubunit of the rod cGMP-gated channel in a family with autosomal recessive retinitis pigmentosa. Hum Genet 108:328-334

Baylor D (1996) How photons start vision. Proc Natl Acad Sci USA 93:560-565

Bradley J, Frings S, Yau K, Reed R (2001) Nomenclature for ion channel subunits. Science 294:2095-2096

Bradley J, Reisert J, Frings S (2005) Regulation of cyclic nucleotidegated channels. Curr Opin Neurobiol 15:343-349

Contessa GM, Orsale M, Melino S, Torre V, Paci M, Desideri A, Cicero DO (2005) Structure of calmodulin complexed with an olfactory CNG channel fragment and role of the central linker: residual dipolar couplings to evaluate calmodulin binding modes outside the kinase family. J Biomol NMR 31:185-199

Fain GL, Matthews HR, Cornwall MC, Koutalos Y (2001) Adaptation in vertebrate photoreceptors. Physiol Rev 81:117-151

Fesenko EE, Kolesnikov SS, Lyubarsky AL (1985) Induction by cyclic GMP of cationic conductance in plasma membrane of retinal rod outer segment. Nature 313:310-313
Finn JT, Krautwurst D, Schroeder TY, Chen TY, Reed RR, Yau KW (1998) Functional co-assembly among subunits of cyclic-nucleotide-activated, nonselective cation channels, and across species from nematode to human. Biophys J 74:1333-1345

Halling DB, Georgiou DK, Black DJ, Yang G, Fallon JL, Quiocho FA, Pedersen SE, Hamilton SL (2009) Determinants in CaV1 channels that regulate the $\mathrm{Ca} 2+$ sensitivity of bound calmodulin. J Biol Chem 284:20041-20051

Hoeflich KP, Ikura M (2002) Calmodulin in action: diversity in target recognition and activation mechanisms. Cell 108:739-742

Hsu YT, Molday RS (1993) Modulation of the cGMP-gated channel of rod photoreceptor cells by calmodulin. Nature 361:76-79

Ikura M, Spera S, Barbato G, Kay LE, Krinks M, Bax A (1991) Secondary structure and side-chain $1 \mathrm{H}$ and $13 \mathrm{C}$ resonance assignments of calmodulin in solution by heteronuclear multidimensional NMR spectroscopy. Biochemistry 30:9216-9228

Kainosho M, Torizawa T, Iwashita Y, Terauchi T, Mei Ono A, Guntert P (2006) Optimal isotope labelling for NMR protein structure determinations. Nature 440:52-57

Shen Y, Delaglio F, Cornilescu G, Bax A (2009) TALOS+: a hybrid method for predicting protein backbone torsion angles from NMR chemical shifts. J Biomol NMR 44:213-223

Shuart NG, Haitin Y, Camp SS, Black KD, Zagotta WN (2011) Molecular mechanism for 3:1 subunit stoichiometry of rod cyclic nucleotide-gated ion channels. Nat Commun 2:457

Trudeau MC, Zagotta WN (2002) Mechanism of calcium/calmodulin inhibition of rod cyclic nucleotide-gated channels. Proc Natl Acad Sci U S A 99:8424-8429

Trudeau MC, Zagotta WN (2003) Calcium/calmodulin modulation of olfactory and rod cyclic nucleotide-gated ion channels. J Biol Chem 278:18705-18708

Turner M, Anderson DE, Nieves-Cintron M, Bartels P, Coleman AM, Yarov V, Bers DM, Navedo MF, Horne MC, Ames JB, Hell JW (2020) a-Actinin-1 promotes gating of the L-type Ca2+ Channel CaV1.2. EMBO J 39:e102622

Wishart DS, Sykes BD, Richards FM (1992) The chemical shift index: a fast and simple method for the assignment of protein secondary structure through NMR spectroscopy. Biochemistry $31: 1647-1651$

Publisher's Note Springer Nature remains neutral with regard to jurisdictional claims in published maps and institutional affiliations. 